\title{
Biological monitoring: state of the art
}

\author{
Perrine Hoet, Vincent Haufroid
}

Exposure to chemical agents can be assessed either by measuring the concentration of the agent in the air by stationary or personal sampling (ambient monitoring), or by measuring some biological variables (biological monitoring). The term biomarker that has been proposed for a few years is used in a broad sense to include almost any measurement reflecting an interaction between a biological system and an environmental agent, which may be chemical, physical, or biological. ${ }^{1}$ However, there is still some debate about the definition of the term and it is clear that interpretation of the term varies between authors. Strictly speaking, biological monitoring of exposure to chemical agents means measurement of a substance or its metabolites in various biological media. Sometimes, the concept of biological monitoring is extended to include the detection of early reversible non-adverse effects (biological monitoring of effect). The detection of an adverse effect-for example, increased proteinuria-indicates that exposure is or has been excessive and therefore such a measurement is more logically included in a programme of early detection of health impairment due to industrial chemicals rather than in a biological monitoring programme for evaluating exposure. In view of differences between people in susceptibility to xenobiotics, the detection of increased susceptibility to a chemical hazard might also be considered. This implies the use of biological markers able to detect endogenous aquired or inherent limitation of an organism to respond to a challenge of exposure to a specific xenobiotic substance or a group of such substances (biological monitoring of susceptibility). ${ }^{2}$

(Occup Environ Med 1997;54:361-366)

Keywords: biological monitoring; methodology

Ambient monitoring, or biological monitoring, or both? some considerations AMBIENT MONITORING

Ambient monitoring is the most usual method for the assessment of exposure. As ambient measurements have been performed for so many years, analytical methods, exposureeffect and exposure-response relations, and limits values are available for many of the chemicals encountered in the workplace. Ambient monitoring is useful for the detection of acute exposure to dangerous chemicals, the identification of sources of emission, and the evaluation of the efficiency of engineering control measures.

Ambient monitoring is not invasive and a single ambient monitoring operation may prevent overexposure of many people. Atmospheric measurements are, moreover, more relevant than biological monitoring in cases of exposure to substances exhibiting their effect on the site of contact-for example, skin, eye, or respiratory irritants, and respiratory tract carcinogens - and those that are poorly absorbed. Finally, it helps to separate the importance of the contribution of an occupational exposure from non-occupational sources of exposure (leisure activities, environment, cigarette smoking).

\section{BIOLOGICAL MONITORING}

Biological monitoring takes into account the fact that the exposure is not always constant: air concentrations are seldom stable but fluctuate all the time, moreover the subject moves sometimes from one place to another where the ambient concentration is not necessarily the same. It also takes into account absorption by other routes of exposure than the lungs. Many chemicals can enter the body by absorption through the skin or the intestinal tract; as biological monitoring data gives an estimate of the uptake by all routes of exposure (inhalation, ingestion, skin absorption), the measurement is related to the body burden and hence to the individual risk. Biological monitoring reflects all sources of exposure; not only occupational but also background exposure from dietary habits, smoking, residency, and hobbies. Finally, it takes into consideration the various physicochemical and toxicokinetic factors-for example, the solubility or the particle size of the compound influencing the rate of absorption, the variation in workload entailing variation in the absorption rate, and the capacity of metabolising the substance (absorption, biotransformation, excretion).

In conclusion, ambient and biological monitoring are to be considered as two complementary methods.

\section{Approaches in biological monitoring}

Biological monitoring has been defined as a systematic or repetitive measurement and assessment of workplace agents or their metabolites either in tissues, secretions, excretions, expired air, or any combination of these to evaluate exposure and risk to health 
compared with an appropriate reference. ${ }^{3}$ It can be divided into three sections: (a) biological monitoring of exposure; (b) biological monitoring of effect; and (c) biological monitoring of susceptibility.

BIOLOGICAL MONITORING OF EXPOSURE

The biological monitoring of exposure can be itself subdivided into biological monitoring of internal dose and biological monitoring of effective dose.

\section{Biological monitoring of internal dose}

Biological monitoring of internal dose implies the assessment of the parent compound or its metabolites in biological samples. The media most commonly used are urine and blood but it is also possible to analyse exhaled air, faeces, adipose tissues, hairs, nails, saliva, and milk.

These tests are classified into two subgroups:

\section{Specific methods}

These methods rely on the direct measurement of the unchanged chemicals or their metabolites in biological media. This category includes most tests currently available in routine biological monitoring of exposure to chemicals. The results reflect exposure to the chemical agent under investigation only and indicate if exposure to a given compound has occurred - for example, the urinary measurements of mercury, muconic acid, and mandelic acid for the assessment of exposure to mercury, benzene, and styrene.

Assessment of body or organ burden in vivoRecent methods have been developed to assess directly the amount of chemical stored at the site of accumulation: (a) neutron activationthe cadmium content in the kidneys and the liver have been estimated by neutron activation; (b) $x$ ray fluorescence-the cadmium content in the kidneys and the lead content in bones have been measured by $x$ ray fluorescence. Some findings suggest the existence of a good relation between the cumulative blood lead index and the content of lead stored in the bones.

\section{Non-specific methods}

These tests are used as non-specific indicators of exposure to a group of chemicals-for example, measurement of diazopositive metabolites in urine for monitoring exposure to aromatic amines, the measurement of thioethers in urine to assess exposure to mutagenic and carcinogenic substances, or of the mutagenicity of urine to estimate exposure to such substances. Because of their lack of specificity and the existence of a large individual variability, these tests cannot usually be used to monitor exposure on an individual basis. It is, however, possible that when an adequate control group is used as reference, they may be useful as qualitative tests to identify exposed groups.

\section{Biological monitoring of effective dose}

These tests directly or indirectly estimate the amount of chemical interacting with the site of action (or toxicologically significant target).
The best known test of this category is the measurement of carboxyhaemoglobin induced by exposure to carbon monoxide (or dichloromethane metabolised into carbon monoxide). However, it should be remembered that exposure to carbon monoxide is certainly not specific to occupational activities and that tobacco smoking is a major source of exposure to carbon monoxide.

Studies in this area have been mainly carried out for exposure to potentially genotoxic substances and for development of the measurement of macromolecular adducts. Protein and DNA adducts can be used as indicators of exposure to reactive substances in the DNA of target tissues. Although the amount of DNA resulting from white blood cells or lymphocytes can be limited, proteins, such as haemoglobin or albumin are present in large quantities in human blood (see biological monitoring of mutagenic or carcinogenic substances). DNA adducts can be removed by DNA repair processes or by cell death, but during chronic exposure they often reach steady state levels in carcinogen target tissues.

\section{BIOLOGICAL MONITORING OF NON-ADVERSE}

REVERSIBLE EFFECTS

There are many potential biomarkers for assessing the biochemical effects of chemical agents. Schematically, these tests can be divided into two broad categories. The first category includes the variables that indicate pathological damage-such as biomarkers of liver dysfunction (transaminases) or kidney dysfunction (albumin in urine). The second category comprises those detecting early biochemical changes or responses which are considered as reversible and not adverse.

These are often considered to be biomarkers of exposure. Biological effect monitoring has been defined as the measurement of a reversible biochemical change caused by the absorption of the substance; the degree of chance being below that associated with toxic injury and not associated with a known irreversible pathological effect. ${ }^{4}$ Thus, in this framework, biological monitoring of effects relies on the identification and the measurement of reversible, non-adverse biological effects related to the internal dose. These tests should predict the adverse effects but are to be distinguished from the tests identifying the adverse effects. However, the distinction between adverse and non-adverse biological effects is not always clearcut and is sometimes arbitrary as it may be difficult to evaluate the health significance of an effect. The inhibition of enzymes - such as the $\delta$-aminolaevulinic acid deshydratase (inhibited by lead) or the pseudocholinesterase (inhibited by organophosphates) - are examples of well validated methods.

The measurement of the activity of numerous enzymes in blood has also been widely used, specially with the development of separation techniques of isoenzymes-for example, lactate dehydrogenase ( $\mathrm{LDH})$ - but in these cases they usually indicate adverse effects rather than reversible biochemical changes and are therefore better indicated for early detection of 
a health impairment programme-for example, the measurement of the hepatic enzymes released into the blood to detect liver damage.

The urinary excretion of numerous proteins, enzymes, and biochemical markers-for example, $\alpha 1$ and $\beta 2$-microglobulins, $N$-acetylglucosaminidase, $\beta$-galactosidase, sialic acid, retinol binding protein, thromboxan, kallikrein-has been investigated by many authors in subjects exposed to nephrotoxic substances such as cadmium, lead, and mercury..$^{5-10}$ However, the potential health significance of some of these variables is still unknown. Are they to be considered as reversible non-adverse effects or should they be included in the programme of early detection of health impairment?

\section{BIOLOGICAL MONITORING OF SUSCEPTIBILITY}

A biomarker of susceptibility is an indicator of an inherent or acquired ability of an organism to respond to the challenge of exposure to a specific xenobiotic substance. ${ }^{1}$

For example, the ability to acetylate aromatic amines is genetically determined and shows variation with ethnic origin. It has been suggested that slow acetylators with mutations which result in less functional $\mathrm{N}$-acetyltransferase enzymes, are at increased risk of developing bladder cancer but decreased risk of colorectal cancer when exposed to carcinogenic aromatic amines. ${ }^{112}$ The measurement of such polymorphism in metabolising genes requires the administration of a relevant test drug (sulphamethazine and caffeine have been suggested) and the subsequent measurement of its clearance from the body. An alternative to these metabolic methods relies on direct gene analysis based on new methods in molecular biology (including the polymerase chain reaction) with DNA from lymphocytes and other cells. These techniques allow the detection of genotypes of known polymorphisms involving various enzymes that metabolise xenobiotics. Among these, enzymes associated with cytochrome $P-450$ are of particular interest for interpreting the results of biological monitoring especially if metabolites are responsible for the toxicity of the chemical-for example, alkoxyacetic acid metabolites of ethylene glycol ethers.

A genetically based low level of $\alpha$-antitrypsin activity increases the risk of emphysema from cigarette smoking. ${ }^{13}{ }^{14}$ Such biomarkers should be used preventively rather than after an exposure event.

Many ethical issues, that will not be discussed in this article, have been raised about the use of biological markers, especially about markers of susceptibility.

\section{An example: biological monitoring of} mutagenic or carcinogenic substances Considerable efforts have been made to develop biological markers associated with exposure to potentially carcinogenic chemicals and to establish a relation between the marker and the future health risk. As well as the detection of mutagenic or carcinogenic substances or their metabolites in blood and urine-that is, biological monitoring of internal dose (measurement of the urinary concentration of inorganic arsenic and its methylated metabolites, muconic acid, 4,4'-methylene-bis(2chloroaniline) (MOCA), 1-hydroxypyrene for the assessment of exposure to inorganic arsenic, benzene, MOCA, and polycyclic aromatic hydrocarbons)-different types of biological analyses can be considered for detecting exposure to carcinogens.

ANALYSIS OF THE MUTAGENIC ACTIVITY OF URINE OF EXPOSED WORKERS (SEE NON-SPECIFIC TESTS) Mutagenic activity of urine is considered to be among the non-specific tests-for example, mutagenic activity of nurses handling cytostatic drugs. ${ }^{15-17}$ This test shows large variations between people and is prone to interference from smoking, diet, and drugs. Another point to be underlined is that only mutagenic carcinogens can possibly be detected by this method. Moreover, the mutagenic activity measured in urine is not necessarily a reflection of the genetic alteration in the target organ. It should also be stressed that the compound responsible for the mutagenicity in urine may not be involved in the genotoxic effect in the target organ and conversely, the lack of increased mutagenic activity in urine does not necessarily mean the absence of genotoxic lesions.

\section{ANALYSIS OF THIOETHER DETOXIFICATION} PRODUCTS IN URINE (SEE NON-SPECIFIC TESTS) Urinary thioethers are mainly derived from the reaction of electrophilic chemicals with glutathione. The glutathione conjugates formed are then degraded to yield $\mathrm{N}$-acetyl-Salkylcysteine or mercapturic acids which are excreted in the urine. Several authors have evaluated the possibility of measuring urinary excretion of thioethers to detect exposure to electrophilic substances and their precursors - for example, in petroleum retailers, workers occupied in the petoleum industry, in coke ovens, in asphalt producing or using plants, workers exposed to styrene, and workers exposed to pesticides. ${ }^{18-22}$ There are large variations between and within subjects due mainly to the influence of the excretion of endogenous thioethers, diets, and cigarette smoking. ${ }^{2324}$ Moreover, it seems that a value within the normal range does not exclude exposure to an electrophilic substance. ${ }^{25}$ Therefore, the primary value of this test is its signal function, meaning that when an increase in thioether excretion is found it may be concluded that exposure to such a substance has occurred.

DETERMNATION OF MACROMOLECULAR ADDUCTS (SEE BIOLOGICAL MONITORING OF EFFECTIVE DOSE)

Macromolecular adducts are used both as molecular dosimeters (biomarker of exposure) and to assess the genotoxic potential of chemicals (biomarker of effect). They can be considered as biomarkers of effective dose, the effective dose at a relevant site being the preferred measure over internal dose. 
DNA adducts are formed during the biotransformation of chemical agents to reactive intermediates that are electrophilic and bind covalently to DNA. Unless repaired, such DNA lesions may result in mutations at critical sites during DNA replication, ultimately leading to cancer. Thus, accurate measurement of DNA adducts formed from a (suspected) genotoxic agent in the target organ is expected to indicate its initiating potential. The binding of carcinogens to DNA and the resulting formation of DNA adducts can be directly shown by identifying these adducts either in cellular DNA (in white blood cells or lymphocytes), in its degradation products excreted in urine, or indirectly by measuring the adducts formed with non-target macromolecules such as proteins (albumin, haemoglobin). It has indeed been suggested that monitoring of the reaction products formed with amino acids in proteins might provide an indication of the extent of DNA alkylation. ${ }^{26}$ The amino acids in haemoglobin that may react with genotoxic agents are those with nucleophilic side chains (lysine, histidine, cysteine) and the $\mathrm{N}$-terminal amino acid (valine). As they are not repaired haemoglobin adducts reflect the cumulative exposure during the lifetime of the protein (four months). However, as carcinogens may vary in their ability to cross the erythrocyte membrane, the degree of alkylation of serum albumin (lifetime 21 days) might constitute a better index of exposure, at least to some electrophilic compounds.

Macromolecular adducts have been largely used in recent years for the biomonitoring of occupational exposure-for example, to aromatic amines, ethylene oxide, styrene, 1,3butadiene, complex mixtures of polycyclic aromatic hydrocarbons (PAHs) in iron foundries, coke ovens, aluminium plants, and among roofers and surface coating workers. ${ }^{26-28}$

They seem very promising methods but much research is still needed before they can be introduced in the routine biological monitoring of industrial workers.

\section{ANALYSES OF GENOTOXICITY (SEE BIOLOGICAL} MONITORING OF EFFECT)

These methods aim to detect the consequences of the interaction of the mutagenic or carcinogenic agent and the genetic material. The various possible methods involve the measurement of chromosomal aberrations, sister chromatid exchanges, unscheduled DNA synthesis, single strand breaks, point mutations, and micronuclei in peripheral blood lymphocytes. ${ }^{29-31}$ As with mutagenic activity in urine and the measurement of thioethers in urine, because of the wide variations between and within subjects and the many potential confounding factors, these tests can only be used at the group level, to detect a group at risk.

\section{DETECTION OF ONCOGENIC PROTEINS}

The identification in urine or plasma of proteins resulting from the activation of an oncogene has been suggested to detect specific mutations. For example, PAHs have been shown to cause specific mutational lesions that can lead to the activation of the ras oncogene and expression of its p21 protein product. ${ }^{32}$ Much research is still needed before this test can be introduced in the routine biological monitoring of industrial workers.

\section{Main prerequisites for the development of biological markers and their interpretation}

KNOWLEDGE OF THE TOXICOKINETICS OF THE CHEMICAL

Biological monitoring mainly relies on the knowledge of toxicokinetic data. This includes information on the rate of absorption, distribution, sites of accumulation, biotransformation, and routes of excretion to make the best choice about the substance to be measured as well as the biological media and the time of sampling.

The toxicokinetics of an agent are influenced by many physiological and pathological factors (age, sex, food, drink, smoking, state of health, intake of drugs) that must be taken into account when interpreting a result. For example, chronic intake of ethanol usually stimulates drug metabolising enzymes and hence the biotransformation of other absorbed chemical agents, whereas during or shortly after a large alcohol intake entailing a high concentration of alcohol in the body, there seems to be an inhibitory effect on the metabolism of xenobiotics. ${ }^{33}$

Perturbation of renal clearance, or large or restricted beverage intake, may also be responsible for misinterpretation of urinary results (urine samples that are too dilute or too concentrated).

It is also important to underline that physicochemical factors also play an important part in the rate of absorption of a substance. For instance, measurement of nickel in urine is only a qualitative indicator of exposure to soluble nickel compounds but certainly not to insoluble compounds. However, the important health effects caused by exposure to nickel are mainly local (skin, respiratory tract), and the real interest of the dosage of nickel in urine might be questionable.

Practically, the variable most often used to characterise the behaviour of the biological marker in the body is the elimination half lifethat is, the time needed to excrete half the amount of the substance. A substance with a half life of less than two hours is not suitable for monitoring as timing is too critical. When the half life lies between two and 10 hours the optimum sampling time is at the end of the shift or the beginning of the next shift (less influenced by peak exposure). When the substance under investigation has a half life between 10 and 100 hours, it provides an evaluation of the total amount of the chemical absorbed during the preceding day (sampling after 16 hours) or during the week (end of week sampling). For cumulative substances-such as heavy metals - the time of sampling is not critical. ${ }^{34}$ In this case, there is indeed a slow release from a deep compartment that has accumulated the chemical substance over a long period and that may result in an endogenous exposure of target organs-for 
example, the release of lead from the bones that is increased in some circumstances-such as osteoporosis and bone fracture.

Animal studies can be used to show toxicokinetic patterns of a chemical but confirmatory studies in humans are needed before extrapolation of these patterns from experimental data. Physiologically based pharmacokinetic models taking account of the variability of numerous exposure and physiological factors (intensity and duration of exposure, workload, body build, liver and renal function) may also provide valuable tools when trying to establish relations between external exposure and internal dose. ${ }^{35}$

KNOWLEDGE OF THE TOXICODYNAMICS

The knowledge of the non-adverse biological changes and the potential harmful effects should also be considered as a prerequisite for the accurate determination of a tolerable biological action level and the interpretation of the results. The determination of the concentration of the substance at which the effect is expected to occur (dose-effect relation) and the percentage of people showing these effects at each dose level (dose-response relation) are also fundamental data.

In the occupational setting exposure is often to a mixture of substances. This may entail variations in terms of toxicokinetic and toxicodynamic processes, which must be taken into account when interpreting the results (the possible physicochemical interactions between the substances, the effects that one agent may have on the absorption, biotransformation, and excretion of the other).

REFERENCE LEVELS

Results are to be interpreted by comparison with reference limits values.

\section{Reference value observed in an unexposed population}

The substance under investigation may be present in the biological fluids in the general population without any occupational exposure. These reference values must be derived from a population similar in terms of race, age, sex, and environmental factors-such as air pollution, smoking habits, drugs, and dietary factors. Such an approach is largely used in clinical chemistry and allows identification of exposed people. It needs a sufficiently large sample of the population. Failure to know the main sources of variation limits the validity.

Another limitation is that for some chemicals, the detection limit of the analytical methods available is not sufficiently low to assess the concentration in non-occupationally exposed people.

\section{Biomonitoring action level for an exposed population}

Biomonitoring action levels allow the uptake of a certain amount of a chemical agent which is considered to be acceptable for the preservation of the health of the subject.

For most substances these levels are derived from the occupational exposure limits in air, and are the concentration of the agent that will occur in the body fluids after an eight hour time weighted average exposure at the occupational exposure limit. Biological monitoring performed under these conditions is much more an assessment of the exposure intensity than of the potential risk to health.

For chemicals that are extensively absorbed through the skin, biological action value based on the relation between the occupational limit value in the air and the concentration in the biological media may underestimate the importance of exposure-for example, glycol ethers.

Ideally the biological action levels should be health based derived from long term follow up studies of workers exposed to eight hours a day, five days a week, over a working life without adverse effects. In some situations, a quantitative relation between internal dose and adverse health effect has actually been identified-for instance, for lead in blood, cadmium in urine, or carboxyhaemoglobin. In these cases, the biological variable can be considered as an indicator of health risk. When the internal dose is quantitatively related to both adverse effects and external exposure, the biological variable provides information on both exposure and health risk.

The biological action level may also be derived from good working practices. In this approach, the limit reference is established in comparison with the concentration of the chemical (or its metabolites) found in biological specimens of workers exposed to the substance under investigation when good working practices are adhered to. This approach is largely used, for practical reasons, for substances extensively absorbed through the skin.

\section{Conclusion}

Ideally, the biological variable:

- Specifically assesses the exposure to the chemical substance under investigation

- Is sufficiently sensitive to detect people exposed to low level of chemicals

- Varies quantitatively with the intensity of exposure and the risk of development of adverse effects and there is a clear cut relation with the degree of exposure

- Yields more information on potential health risk than information obtained by ambient monitoring

- Is stable enough to allow storage of the sample for a certain period

- Does not entail sampling methods involving too much discomfort or any health risk for the subject

- Can be measured by an analytical method with sufficient accuracy, specificity, sensitivity

- Does not need too time consuming, complex, or expensive methods.

World Health Organization. Biomarkers and risk assessment concepts and principles. International programme on chemical . WHO, 1993. (Environmental Health Criteria 155. .)

2 Lauwerys R, Hoet P. Industrial chemical exposure. Guidelines for biological monitoring. Boca Raton: Lewis, 1993;1-13. 3 Berlin A, Yodaiken R, Hennman B, eds. Assessment of toxic Berlin A, Yodaiken R, Hennman B, eds. Assessment of toxic
agents at the workplace. Role of ambient and biological monitor- 
ing. Proceedings of NIOSH-OSHA-CEC Seminar, Luxemhourg, December 1980. Boston: Martinus Nijhoff Publishers 1984:X-XXVI.

4 Health and Safety Executive. Biological monitoring for chemical exposures in the workplace.London: HMSO, 1992. (Environmental Hygiene Series Guidance Note EH56.)

5 Cardenas A, Roels H, Bernard A, Barbon R, Buchet JP, Lauwerys $\mathbf{R}$, et al. Markers of early renal changes induced by industrial pollutants: application to workers exposed to lead. Br F Ind Med 1993;50:28-36.

6 Cardenas A, Roels H, Bernard A, Barbon R, Buchet JP Lauwerys $\mathrm{R}$, et al. Markers of early renal changes induced by industrial pollutants: application to workers exposed to mercury vapour. $\mathrm{Br} \mathcal{F}$ Ind Med 1993;50:17-27.

7 Roels H, Bernard A, Cardenas A, Buchet JP, Lauwerys R Hotter G, et al. Markers of early renal changes induced by industrial pollutants: application to workers exposed to industrial pollutants: application to work
cadmium. $\mathrm{Br} ₹$ Ind $\mathrm{Med}$ 1993;50:37-48.

8 Chia K, Mutti A, Tan C, Ong H, Jeyaratnam J, Ong N, Lee E. Urinary $\mathrm{N}$-acetyl- $\beta$-D-glucosaminidase activity in workers exposed to inorganic lead. Occup Environ Med 1994;51: 125-9.

9 Langworth S, Elinder C, Sundquist K, Vesterberg O. Renal and immunological effects of occupational exposure to inorganic mercury. Br f Ind Med 1992;49:394-401.

10 Kido T, Honda R, Yamada Y, Tsuritani I, Ishizaki M, Nogawa K. al-Microglobulin determination in urine fo the early detection of renal tubular dysfunctions caused by the early detection of renal tubular dysfunctions caused

11 Guengerich F. Interindividual variation in biotransformation of carcinogens: basis and relevance. In: Groopman J, Skipper P, eds. Molecular dosimetry end human cancer analytical, epidemiological and social considerations. Boca Raton: CRC Press, 1991:27-52.

12 Kadlubar F, Butler M, Kaderlik K, Chou HS, Lang N. Polymorphisms for aromatic amine metabolism in humans: relevance for human carcinogenesis. Environ Health Perspect 1992;98:69-74.

13 Laurell CB, Eriksson S. The electrophoretic a1-globulin pattern of serum in a1-antitrypsin deficiency. Scand $\mathcal{F}$ Clin Lab Invest 1963;15:132-40.

14 Janoff A. Elastase and emphysema. Current assessment of the protease-antiprotease hypothesis. Am Rev Respir Dis 1985;132:417-33.

15 Falck K, Grohn P, Sorsa M, Vainio H, Heinonen E, Holst L. Mutagenicity in urine of nurses handling cytostatic drugs. Lancet 1979; 1:1250-1.

16 Anderson R, Puckett W, Dana W, NGuyen T, Theiss J, Matney T. Risk of handling injectable antineoplasic agents. American fournal of Hospital Pharmacology 1982;39:18817 .

17 DeMeo $M$, Merono S, DeBaille A, Botta A, Laget $M$ Guiraud H, Dumenil G. Monitoring exposure of hospita personnel handling cytostatic drugs and contaminated materials. Int Arch Occup Environ Health 1995;66:363-8.

18 Burgaz S, Borm P, Jongeneelen F. Evaluation of urinar excretion of 1-hydroxypyrene and thioethers in worker exposed to bitumen fumes. Int Arch Occup Environ Health 1992;63:397-401.

19 Van Wellie R, Van Marrewijk C, De Wolff F, Vermoulen N. Thioether excretion in urine of applicators exposed to 1,3 dichloropropene: a comparison with urinary mercapturic excretion. Br f Ind Med 1991;48:492-8.
20 Reuterwall $\mathrm{Ch}$, Aringer L, Elinder C, Rannug A, Levin JO, Juringe $L$ Onfelt A. Assessment of genotoxic exposure in Swedish coke oven work by different methods of biological monitoring. Scand $\mathcal{f}$ Work Environ Health 1991;17:123-32.

21 Aringer L, Lof A, Elinder C. The applicability of the measurement of urinary thioethers. A study of humans exposed to styrene during diet standardization. Int Arch Occup Environ Health 1991;63:341-6.

22 Hagmar L, Bellander T, Persson L, Holmen A, Attewell R, Hogstedt B, Skerfving S. Biological effects in a chemical factory with mutagenic exposure. III Urinary mutagenicity and thioether excretion. Int Arch Occup Environ Health 1988;60:453-6.

23 Aringer L, Lidums V. Influence of diet and other factors on urinary levels of thioethers. Int Arch Occup Environ Health 1988;61:123-30.

24 Lafuente A, Mallol L. Urinary thioethers in low tar cigarette smokers. Public Health 1986;100:392-6.

25 Van Doorn R, Leijdekkers C, Bos R, Brouns R, Henderson P. Detection of human exposure to electrophilic compounds by assay of thioether detoxication products in urine. Ann Occup Hyg 1981;24:77-92.

26 Hemminki K, Dipple A, Shuker D, Kadlubar F, Segerback $\mathrm{D}$, Bartsch H, eds. DNA adducts: identification and biological significance. Lyon: IARC, 1994. (IARC Sci Publ No 125.)

27 Bartsch H, Hemminki K, O'Neill I. Methods for detecting DNA damaging agents in humans: applications in cancer epidemiology and prevention. Lyon: IARC, 1988. (IARC Sci Publ No 89.)

28 Philips D, Castegnaro M, Bartsch $\mathrm{H}$. Postlabelling methods of DNA adducts. Lyon: IARC, 1993. (IARC Sci Publ No 124.)

29 Forni A. Chromosomal aberrations in monitoring exposure to mutagens-carcinogens. In: Berlin A, Draper M, Hemminki $\mathrm{K}$, Vainio $\mathrm{H}$, eds Monitoring human exposure to carcinogenic and mutagenic agents. Lyon: IARC, 1984:247-58. (IARC Sci Publ No 59.)

30 Sorsa $M$. Monitoring sister chromatic exchange and micronuclei as biological endpoints. In: Berlin A, Draper M, Hemminki K, Vainio H, eds. Monitoring human exposure to carcinogenic and mutagenic agents. Lyon: IARC, 1984;24758. (IARC Sci Publ No 59.)

31 Sorsa M, Wilbourn J. Vainio H. Human cytogenetic damage as a predictor of cancer risk. In: Mechanisms of carcinogenesis in risk identification. Vainio $\mathrm{H}$, Magee $\mathrm{P}$, McGregor $\mathrm{D}$ McMichael A, eds. Lyon: IARC, 1992:543-54. (IARC Sci Publ No 116.)

32 Brandt-Rauf $P$. Advances in cancer biomarkers as applied to chemical exposures: the ras oncogene and p21 protein and pulmonary carcinogenesis. F Occup Med 1991;33:951-5.

33 Fiserova-Bergerova V. Biological monitoring. VIII: interference of alcoholic beverage consumption with biological ence of alcoholic beverage consumption with biological monitoring of occupational exposure to indust

34 Bernard A. Biokinetics and stability aspects of biomarkers: recommendations for application in population studies. Toxicology 1995;101:65-71.

35 Droz P, Fiserova-Bergerova V. Biological monitoring Vl: pharmacokinetic models used in setting biological exposure indices. Appl Occup Environ Hyg 1992;7:574-80. 